\title{
0 processo produtivo do jornal Zero Hora: a estratégia do "localismo"
}

RESUMO

$\mathrm{O}$ artigo busca compreender como funciona o fazer jornalístico do jornal Zero Hora $(\mathrm{ZH})$, do grupo Rede Brasil Sul de Comunicações, a partir do seu processo produtivo. Parte do entendimento de que o jornalismo, especialmente o impresso, tem passado por mudanças significativas nas últimas décadas, tanto no seu processo produtivo, como no produto final, buscando se readequar às exigências competitivas do mercado. No caso de Zero Hora, o estudo procura identificar os movimentos do jornal para sua afirmação e manutenção da hegemonia entre os diários do estado onde circula, adotando, entre outras estratégias, um critério de noticiabilidade particular, o "localismo".

\section{PALAVRAS-CHAVE}

- jornalismo

- rotinas produtivas

- jornal impresso

\section{ABSTRACT}

This article attempts to understand the making of journalistic works at Zero Hora (ZH) newspaper (owned by Rede Brasil Sul de Comunicações) from its productive process. It starts with the assumption that journalism has undergone several significant changes in recent decades, particularly on its written form - either in its productive process or in the final product - and in its endless efforts to meet the demands of a competitive market. The purpose of this research in Zero Hora's case is to identify the newspapers' actions for establishing and maintaining its leadership in the states where it is published by means of taking the criterion of particular news, also known as "localism," along with other strategies.

\section{KEY WORDS}

- journalism

- production routine

- printed newspaper

\section{$\mathrm{P}$} arte-se, neste artigo, do entendimento da notícia ${ }^{1}$ como uma construção social e cultural. $\mathrm{O}$ jornalismo constrói realidade dando-lhe forma narrativa e sentido, a partir da interação entre imprensa, sujeitos e instituições representantes de diferentes campos sociais, difundindo-a, convertendo-a em realidade pública. Ainda, a notícia é compreendida como produto mercadológico, sujeito às regras de mercado, tendo um processo de produção, assim como os demais bens culturais.

Como processo produtivo, a notícia tem um "modo de fazer" comum à imprensa em geral, com rotinas, norteadores éticos e deontológicos, mas também com especificidades do veículo de comunicação em questão - linha editorial, rotinas próprias, relações entre os produtores, com esses e a sociedade e da empresa com os anunciantes. São condições de produção forjadas ao longo da trajetória da instituição imprensa.

Sendo assim, o estudo das rotinas de produção de Zero Hora, do grupo Rede Brasil Sul de Telecomunicações, é feito a partir dos aspectos da competitividade industrial, competência comunicativa/interpretativa, níveis e fases de decisão editorial, ideologias profissionais e rotinas de produção (MARTÍN-BARBERO, 2003) do jornal ${ }^{2}$.

\section{RBS e o pós-fordismo}

A reorganização do capitalismo, ocorrida nas últimas décadas, e suas implicações têm afetado o fazer jornalístico. As transformações originam-se da adequação das empresas de comunicação aos processos capitalistas globais, como forma de garantia de sustentação no mercado, e à introdução de novas tecnologias da comunicação e informação, que culminam na digitalização dos dados e dos processos e na convergência das mídias.

Ambos fatores interferem na produção jornalística, marcam desde a forma de confecção da notícia - mediada pelo aparato tecnológico informacional e por nova divisão de funções no trabalho e novas relações de trabalho. Também dizem respeito à linguagem com novas mídias influenciando os meios impressos, e interferem no conceito de notícia e no entendimento do que seja interesse público - com os valores-notícias muito mais voltados para a prestação de serviços e o entretenimento. Além disso, ainda o visual dos produtos midiáticos - ampliando espaço para a imagem nos jornais - e a relação mais próxima da publicidade e do marketing com o jornalismo. Determinam, também, a influência dos poderes econômico e político sob a atividade e as funções e o papel do jornalista, até a ética do jornalismo de forma a perpassar todo o campo da mídia.

\section{Ângela Felippi


As transformações perpassam todo campo da mídia. Novas tecnologias e convergência, concentração de propriedade, desregulamentações e privatizações, entrada de capital estrangeiro, quebra de barreiras geográficas de operação, atuação em diversas áreas das comunicações, entre outras são algumas das características desse momento, comuns aos demais setores de produção na fase do capitalismo tardio, e classificadas como marcas do sistema pós-fordista ${ }^{3}$ de produção de bens (CAPPARELLI; LIMA, 2004).

Como conglomerado de comunicação, a RBS ${ }^{4}$ está nesse processo. Foi uma das primeiras organizações de comunicação do País a operar no sistema pósfordista (SANTOS, 1999). Como a maioria dos grupos nacionais com certa concentração de propriedade na área das comunicações, principalmente de televisão, sua constituição enquanto grupo se deu dentro do fordismo, nos anos 70 e 80 do século passado, investindo na produção massiva de entretenimento e informação. O fundador, Maurício Sirotsky Sobrinho, soube aproveitar o momento para constituir o que possibilitaria, no futuro, a hegemonia comunicacional da RBS no Rio Grande do Sul (e mais tarde em Santa Catarina) e o papel de consolidador da indústria cultural gaúcha, uma rede de emissoras de televisão afiliadas a Globo.

A passagem para o pós-fordismo foi se dando através de ações empresariais visionárias, possibilitadas por condições que davam ao grupo possibilidades de transpor de uma etapa de acumulação para outra. No período, anos de 1990, tinha domínio de mercado e condições financeiras e técnicas de empreender em ramos afins, ampliando os negócios e os estendendo à área de Internet, televisão a cabo, produção segmentada de televisão e à telefonia. Com isso, garantiu a pulverização dos investimentos, buscou diminuir riscos, e tentou evitar que grupos concorrentes dividissem essas novas fatias de mercado (publicitário, inclusive).

Apesar de algumas incursões sem sucesso, como o caso da telefonia, o grupo está entre os oito principais do setor de rádio e televisão do País, sendo a maior em concentração em nível regional e a segunda maior após a Rede Globo, enquadrando-se nos quatro tipos de concentração de propriedade catalogados por Capparelli e Lima (2004), que são: horizontal, vertical, cruzada e em cruz ${ }^{5}$. Hoje, o poderio do grupo é garantido pela concentração de propriedade, pelo grau de desenvolvimento tecnológico, pelo nível de profissionalização da gestão das empresas e dos produtos de comunicação e pela abrangência de transmissão e conseqüentemente de público, mantendo-se no mercado adequando-se aos movimentos do capitalismo global sem perder seu poderio.

\section{ZH e a flexibilização no pós-fordismo}

Se a RBS opera dentro das novas regras mundiais do mercado, Zero Hora, enquanto empresa do grupo, foi se adequando às exigências dos novos tempos para conquistar o papel de jornal de referência e assumir a liderança em circulação frente ao principal concorrente, o centenário Correio do $\mathrm{Povo}^{6}$. Aumentou sua tiragem nos últimos anos ${ }^{7}$, indo contra uma tendência de diminuição das tiragens dos jornais impressos, ampliando o público-leitor, em quantidade e diversidade, racionalizando custos e ampliando mercado e anunciantes. E o fez, segundo Fonseca (2005b) a partir de constantes inovações de gestão, gráficas e editoriais.

Zero Hora foi o primeiro jornal da RBS. Criado em 1964, passou ao controle majoritário da família Sirotsky em 1970. Mas é nos anos 80 do século XX, quando Nelson Sirotsky, filho do fundador, assume o comando, que ocorrem transformações gerenciais, com a colocação de executivos "do mundo dos negócios" na gestão (FONSECA, 2004a:157) e a mudança de perfil do editor, por exemplo, que agrega à sua função tradicional funções gerencias, tanto de recursos humanos, materiais e financeiros.

Da mesma forma, reformas gráficas têm sido responsáveis pela posição que $\mathrm{ZH}$ ocupa no mercado gaúcho de jornais. Rüdiger (1993) registra que Zero Hora foi o primeiro jornal diário do sul do País a ser impresso em off set, a partir de 1969, dentro de um processo de reforma do parque gráfico que o tornou mais competitivo. Constantemente, o jornal vem se reciclando em termos gráficos, sendo que as reformas tendem a valorizar cada vez mais os elementos visuais do jornal em detrimento do texto ${ }^{8}$.

As mudanças editoriais, no processo produtivo e nas relações de trabalho em Zero Hora também têm sido fatores responsáveis pela expansão do jornal. A passagem de jornalista Augusto Nunes pela direção de Redação, de 1989 a 1993, foi um marco para a implementação de mudanças que levaram o processo produtivo do jornal ao pós-fordismo. A missão de Nunes, conforme Schirmer (2004), era tornar Zero Hora um jornal conhecido, respeitado e lido no centro do País e em Brasília. O diretor de Redação mexeu profundamente com a área editorial. Mudou rotinas, perfil dos editores e dos repórteres e fez $\mathrm{ZH}$ atingir a marca de quinto jornal em leitores no País, em $1993^{9}$, dando-lhe a visibilidade nacional.

As reformas que Nunes introduziu foram fazendo a transição para o que Fonseca acredita predominar atualmente em $\mathrm{ZH}$, a produção pós-fordista no jornalismo, a flexibilização das tradicionais formas de produção e de relações de trabalho e no produto final jornal - muito mais voltado para o entretenimento e para a prestação de serviço, denotando uma preocupação com a publicidade e com a conquista de leitores. A informatização, a partir de 1988, e, principalmente, a "reinformatização", em 1995, segundo Capparelli (1997), quando o jornal adquire um software editor de texto, fotos e gráficos, momento de intensificação das mudanças na produção e no trabalho seriam os marcos dessa passagem.

Em decorrência, o jornal foi eliminando funções, flexibilizando outras, gerando o acúmulo de funções 
(o mesmo profissional pode apurar, redigir, diagramar, editar, fotografar), percebido durante a observação feita à Redação. Na produção pós-fordista, jornalistas passam a ser co-responsáveis pelo processo produtivo, recebendo, inclusive, fazendo parte do Plano de Participação nos Resultados do jornal. No entanto, especialmente nas relações de trabalho, mantém-se até a atualidade algumas características do fordismo: jornada de trabalho fixa, contrato de exclusividade que o jornal exige do jornalista e padronização das atividades nas distintas editorias.

\section{Produção da notícia e o "localismo"}

A estrutura e a ideologia da organização não determinam totalmente o produto final, no entanto, há marcas dos constrangimentos organizacionais, da cultura profissional, das ideologias em circulação, dos critérios de noticiabilidade, da linha editorial e das rotinas e prazos de confecção do jornal no produto.

Buscamos compreender os processos decisórios do jornalismo e o modo como o jornal é feito por meio de três aspectos: a cultura jornalística, os valores-notícia e as rotinas de produção. Em relação à cultura jornalística, Zelizer (2000) afirma que quando o jornalismo se profissionaliza, no século $\mathrm{XX}$, permite-se não só a autoridade para o desempenho da atividade aos jornalistas, como desenvolvimento de normatizações a cerca da produção noticiosa e condutas éticas. Para a autora, os jornalistas foram se constituindo numa comunidade interpretativa, que tem integrantes reunidos "pelo discurso partilhado e pelas interpretações colectivas de acontecimentos públicos relevantes" (2000, p.33). Traquina (2004) acredita que já exista uma comunidade interpretativa transnacional de jornalistas, com cultura profissional, com princípios éticos, valores, símbolos, mitos e normas compartilhados.

Se os jornalistas formam uma comunidade interpretativa mundial, dentro de uma redação específica tendem a formar uma comunidade de jornalistas agregados também pelas particularidades daquele veículo. Nesse sentido, os jornalistas de Zero Hora são reunidos pelos princípios, normas e valores do jornal, que tem valores-notícia, linha editorial, rotina e cultura organizacional próprias. Essa cultura é adquirida no processo de produção, nas reuniões de pauta, nas orientações dos editores, nas trocas e consultas formais e informais entre os repórteres, nos regimes de premiação e sanções cotidianas. A cultura jornalística deixa traços no jornal, o que se efetiva em boa medida a partir dos valores-notícia. No caso de ZH, algumas de suas particularidades vêm da sua linha editorial, com orientações e critérios de noticiabilidade próprios, especialmente um, denominado "localismo", que está relacionado com nosso objeto de estudo.

Localismo. Esse critério nos rege muito no dia-adia. O localismo para nós é muito forte, muito aguçado, talvez mais do que em outros veículos. (Ricardo Stefanelli, Editor-chefe)
Durante as entrevistas e observação da rotina em Zero Hora, editores enumeraram os principais valores-notícia, comuns à imprensa, e um particular do jornal, o "localismo". Segundo eles, o jornal busca, por meio desse valor-notícia considerado um dos mais determinantes na escolha dos assuntos a serem noticiados, dar conta dos interesses de seu público, os nascidos ou habitantes do espaço físico circunscrito no Rio Grande do Sul, fazendo com que os mesmos tomem conhecimento dos fatos ocorridos no estado ou relacionados a ele, os vejam no jornal, se vejam ou vejam os seus próximos. O critério se aproxima de valores-notícia tradicionais do jornalismo, como "proximidade" e "interesse", mas é diferente, porque constituído na prática no jornal e que o marca e distingue.

Pudemos entender que se enquadram no critério do "localismo" tanto os acontecimentos que têm como cenário a região de cobertura do jornal, o Rio Grande do Sul, como os que estão relacionados ao estado, mas não necessariamente ocorrem dentro de seu território físico e os que envolvem pessoas nascidas (gaúchos) ou que de alguma forma são consideradas do Rio Grande do Sul.

Tudo que tem a ver com o Rio Grande do Sul, de alguma forma, ou outra, tem a ver conosco, com o nosso jornalismo.

(...) Nosso objetivo é esse: onde tem um gaúcho, Zero Hora quer estar junto, esteja ele na Indonésia, Sri Lanka, Maldivas, na Copa do Mundo, na guerra do Afeganistão, no Iraque. (Ricardo Stefanelli, Editor-chefe)

Na explicação dos editores, o "localismo" estaria relacionado a uma tendência mundial dos jornais de se voltarem para o local (estado, região ou cidade) onde estão sediados, como forma de sobrevivência.

(...) as pessoas buscam, cada vez mais, a aldeia. Isso são os estudiosos que dizem, e não eu. Todo o jornalismo local é exemplo de jornal que cresce, de emissoras que aumentam a audiência e de rádios que aumentam a audiência. (Ricardo Stefanelli, Editor-chefe)

O localismo vai além de um critério jornalístico, e se constitui para Zero Hora, acreditamos, num caminho de mercado e de captação de leitores ao optar pela sua inserção no local onde está territorialmente inserido, mediante uma construção discursiva que busca interpelar o leitor pelos aspectos identitários e de pertencimento, como indicam as pistas aqui. ZH disputa o leitor com seus concorrentes da Capital e do interior do estado pela forma como representa a realidade e, inserido nela, seu público-leitor (ou boa parte dele), que por sua vez se identifica com essa forma de representação.

Tétu (2002), ao tratar da informação e do espaço público local, acredita que em função da queda do 
número de leitores e outras causas, os jornais regionais vêm tendendo à monopolização e com isso acirrando a disputa pelo território de difusão. Para tal, tendem à "territorialização forçada", tanto dos interlocutores da comunicação, como das referências que caracterizam essa imprensa. Isso faz com que os jornais regionais se queiram "à imagem apenas de seus leitores" (2002, p. 439) ${ }^{10}$. O depoimento da Editorachefe de ZH corrobora essa reflexão.

Se o jornal não entregar um produto que leitor lê e se enxerga, e enxerga o seu vizinho, enxerga suas questões culturais refletidas no jornal ele não vai comprar, ele vai ler outro jornal, não vai servir. Ou ele não compra, ou vai ler outra coisa. (Marta Gleich, Editora-chefe)

$\mathrm{Na}$ esteira do valor-notícia "localismo", ZH tem seguido outra tendência do jornalismo contemporâneo, que é a participação da audiência, por meio de formas de interatividade ou como personagem das notícias. O movimento de dar voz ao leitor vem crescendo no Brasil desde os anos de 1980, com a abertura democrática e a ampliação dos direitos cidadãos e as mudanças tecnológicas e mercadológicas na imprensa (AMARAL, 2004).

Conforme Editora-chefe, Marta Gleich (2004), ZH tem cinqüenta e cinco formas distintas de participação do leitor, que vão desde os meios mais convencionais, como a carta e o telefonema, até os e-mails com sugestões, elogios ou reclamações. Incluem ainda o envio de sugestões de pauta, o envio de fotos, a resposta a concursos promovidos pelo jornal, a participação em seções como a Pelo Rio Grande, criada para dar vazão aos acontecimentos que não tinham status de notícia, segundo critérios do jornal, e, em sua maioria, ocorridos em cidades de pequeno porte em que o jornal não tem acesso aos acontecimentos.

Tem havido uma certa inversão dos processos tradicionais de decisão exclusiva dos jornalistas sobre o conteúdo do jornal, mesmo na imprensa de referência, balizado pelo mercado, que se reflete na criação de formas de participação do leitor, muito mais ritualísticas do que democratizantes, porém que têm efeito sobre a aceitação do jornal pelo leitor.

Outro traço da linha editorial de $\mathrm{ZH}$ diz respeito à idéia de comunidade que pretende criar e de papel na defesa dos interesses dessa comunidade. Em termos institucionais, o posicionamento se materializa em campanhas que o grupo RBS como um todo adere ou cria, e que no jornal viram critério de seleção de fatos que se transformam em notícias, reportagens, artigos, crônicas, comentários entre outros textos. De acordo com as falas dos editores, ser "localista" significaria dar vazão aos acontecimentos jornalísticos de interesse dos gaúchos e do Rio Grande do Sul.

(...) o jornal tem de defender os interesses de sua comunidade, da comunidade onde circula. (Mar- celo Rech, Diretor de Redação)

Esse desdobramento do "localismo" justifica posturas editoriais em determinadas coberturas jornalísticas e interesses que o jornal acaba por defender, tentando torná-los, por meio do discurso jornalístico, interesses de toda uma comunidade construída pelo jornal.

Aliado aos critérios de noticiabilidade, onde se insere a questão do localismo, também contribuem para sua internalização na redação, as rotinas produtivas garantem o cumprimento do processo produtivo dentro dos prazos e normas estabelecidas pelo jornal. A rotina de produção envolve o consórcio das práticas jornalísticas, dos gêneros e dos prazos de produção. A constituição de uma rotina de produção é garantida por saberes práticos interiorizados, que se sedimentam ao longo do tempo, e fazem parte da cultura jornalística, materializada no produto jornalístico.

Juntamente a rotina produtiva, assim como os valores-notícia e a cultura jornalística se entrelaçam no processo produtivo a fim de garantirem o projeto do jornal. No caso do jornal, o projeto editorial visa estabelecer, por meio das notícias, um vínculo com a comunidade onde está inserida. É projeto mercadológico de conquista de leitores, de relação com a concorrência, relacionado com outras práticas editoriais e de gestão, como a interiorização do jornal, conseqüente atenção aos acontecimentos que ocorrem fora da região Metropolitana.

\section{Considerações finais}

Os movimentos globais da economia, da cultura e da sociedade têm levado as empresas de comunicação à procura de alternativas para a sobrevivência econômica e para a conquista ou manutenção da sua inserção na sociedade. Os jornais impressos são um dos suportes midiáticos que mais têm sofrido com essas transformações.

Zero Hora desenvolveu uma estratégia para sobrevivência mantendo-se focada no seu local de circulação, produzindo-se para um leitor "imaginado" do Rio Grande do Sul, que vai constituindo e sendo constituído pelo jornal. Organizou suas rotinas de produção noticiosa, seus valores-notícias e a cultura profissional particular do veículo em torno disso, elegendo para tal o "localismo" como balizador das escolhas diárias dos acontecimentos jornalísticos e da construção discursiva dada aos mesmos, privilegiando os acontecimentos que tenham relação com a região de abrangência da cobertura e circulação do jornal, buscando construir uma comunidade dos seus leitores.

Os jornalistas, ao escolherem uma pequena parte dos acontecimentos considerados noticiáveis, impedem outros tantos de existirem publicamente, na medida em que o jornalismo é, atualmente, a grande forma de conhecimento que a sociedade tem, constituindo o imaginário social. Tendo como mediador das escolhas o critério do "localismo", $\mathrm{ZH}$ acaba por contribuir para a construção da identidade sobre o seu 
leitor, o morador do Rio Grande do Sul, e sobre o local onde atua. mfamecos

\section{NOTAS}

1. Notícia é usada, aqui, referindo-se aos textos jornalísticos de um modo geral, independente do gênero.

2. Para esse estudo, como técnicas de pesquisa, além da pesquisa bibliográfica, valemo-nos de entrevistas com profissionais do jornal e observação da rotina da Redação. As entrevistas ocorreram em dois momentos distintos, sendo o primeiro, em dezembro de 2004, e o segundo, em janeiro de 2006, quando também aconteceu a observação da rotina de produção. Na primeira ida a campo, em 2004, realizamos entrevistas com os editores-chefe Marta Gleich e Ricardo Stefanelli. Essas primeiras entrevistas tiveram caráter exploratório e de levantamento de dados, de modo que nos forneceram elementos para a pesquisa e também nos levaram, mais tarde, a entrevistar um novo conjunto de atores no jornal. Em janeiro de 2006, foi realizada observação da rotina de produção durante dois dias na Redação de ZH e feitas entrevistas com o Diretor de Redação, Marcelo Rech, com o Gerente de Circulação, Walter Bier, e com o Analista de Mercado, Marcelo Xavier

3. O pós-fordismo ou regime de acumulação flexível, segundo Harvey (1996), seria a denominação de uma nova etapa do capitalismo global, que começa a acontecer a partir da crise do petróleo de 1973, e que sucede a fase do fordismo. O pósfordismo se "apóia na flexibilidade dos processos de trabalho, dos mercados de trabalho, dos produtos e dos padrões de consumo" (1996, p.140).

4. A RBS é um grupo familiar de propriedade dos Sirotsky. Possui - no Rio Grande do Sul e em Santa Catarina - sete jornais, 24 estações de rádio $\mathrm{AM}$ e FM, dois portais de Internet, 17 emissoras de televisão afiliadas à Rede Globo, duas emissoras locais denominadas comunitárias e um canal veiculado nacionalmente voltado para o segmento rural, além de gravadora de discos, empresa de distribuição, produtora de vídeo, assessoria em marketing para jovens e organização de eventos. O grupo iniciou em 1957, com a Rádio Sociedade Gaúcha (Gaúcha AM), sendo que em 1962 foi criada a TV Gaúcha, que mais tarde se afiliou a Globo. Aos poucos, novas emissoras de rádio, de televisão e jornais foram sendo adquiridos ou criados, além de outros empreendimentos de comunicação, e o grupo foi se expandindo para Santa Catarina, onde, assim como no Rio Grande do Sul, possui a hegemonia no setor.
5. Levantamento de Capparelli e Lima (2004), com fontes pesquisadas em 2002, apontam a Rede Globo com 32 emissoras de televisão e 20 de rádio. Após, em nível nacional, ficaria o grupo Bandeirantes, da família Saad, com 12 emissoras de TV e 21 de rádio. No período, a RBS estava com 21 emissoras de televisão e 24 de rádio. Sobre a concentração de propriedade das comunicações, os autores trazem a seguinte catalogação: horizontal, vertical, cruzada e em cruz. A primeira seria a oligopolização ou monopolização na mesma área do setor; a segunda, vertical, seria a integração de várias etapas da produção (produção, veiculação, distribuição de determinado produto, por exemplo); a terceira, propriedade cruzada, significaria a detenção de várias mídias por um mesmo grupo; e a em cruz daria conta da reprodução, em nível local e regional, da propriedade cruzada (um exemplo é o da Rede Globo e suas afiliadas, quase sempre hegemônicas na região onde atuam e reproduzem e divulgam os produtos "globais").

6. Desde que Zero Hora passou a disputar com o Correio do Povo a posição de liderança na venda de jornais no Rio Grande do Sul a partir de 1982 (Rüdiger, 1993), os dois jornais chegaram a disputar o topo da vendagem mês a mês. Segundo o Analista de Mercado de ZH, Marcelo Xavier (2006), desde 2004, Zero Hora teria ultrapassado o concorrente e mantido a posição de liderança.

7. A circulação de Zero Hora é de 171.025 exemplares, sendo 151.131 correspondentes a assinaturas e 19.894 à venda avulsa. A tiragem fica em 191.680. Os dados são de agosto de 2006, do Índice de Verificação de Circulação (IVC), sendo a média ponderada da semana, fornecidos pelo setor de Circulação do jornal. Ainda fornecido pelo jornal, tendo como fonte o Ibope 2005 (GDE POA jul a set de 2005 / Interior RS out de 2005), o número de leitores do jornal é de 2.053.046

8. A mais recente reforma gráfica de $\mathrm{ZH}$, por exemplo, ocorrida em 2005, que também envolveu alterações no projeto editorial, teve como características o aumento do número de páginas com seleção de cores, a ampliação do tamanho e da quantidade de fotos, o aumento do uso de recursos visuais na diagramação, a diminuição do tamanho dos textos e a criação de pequenas seções fixas (ou fixas por um período), incluindo seções que ampliam a participação do leitor.

9. Berger (1998) traz os dados do Ibope de agosto de 1993, que indicam o número de leitores dos principais jornais do País. Zero Hora, no período, estava com 895.100, vindo após O Dia, O Globo, Folha de São Paulo e O Estado de São Paulo. 
10. Para Tetú (2002), local é o espaço demarcado pela proximidade (incluindo a teleproximidade), pelo pertencimento a um grupo social (com marcas de solidariedade) e pela participação (que garante o pertencimento).

\section{REFERÊNCIAS}

AMARAL, Márcia Franz. Lugares de fala do leitor no Diário Gaúcho. Tese (Doutorado em Comunicação e Informação) - Faculdade de Biblioteconomia e Comunicação Universidade Federal do Rio Grande do Sul, Porto Alegre, 2004.

BERGER, Christa. Campos em confronto: A terra e o texto. Porto Alegre: UFRGS, 1998.

CAPPARELLI, Sérgio. Zanzibar de novas tecnologias: imprensa regional e Zero Hora. In Temas Contemporâneos em Comunicação. São Paulo: Edicom-Intercom, 1997. p. 109-126.

- Venício A. de. Comunicação e televisão: Desafios da pós-globalização. São Paulo: Hacker, 2004.

FONSECA, Virgínia Pradelina da Silveira. $O$ jornalismo na lógica do capital: mediação ou prestação de serviço? Disponível em: www.facom.ufba.br/pos/gtjornalismo/doc/ virginiafonseca2004.doc. Acesso em: 19 jan 2005a.

—. Jornalismo no conglomerado da mídia. A reestruturação produtiva sob o capitalismo global. Tese (Doutorado em Comunicação e Informação). Faculdade de Biblioteconomia e Comunicação. Porto Alegre: UFRGS, 2005 b.

MARTÍN-BARBERO, Jesús. Dos meios às mediações. Rio de Janeiro: UFRJ, 2003.

RÜDIGER, Francisco. Tendências do jornalismo. Porto Alegre: Editora da Universidade/Ufrgs: 1993.

SANTOS, Susy dos. RBS: convergência das teles e da TV a cabo. In: CAPPARELLI, Sérgio et al. Enfim, sós - A nova televisão do Cone Sul. Porto Alegre: LP\&M/CPPq, 1999. 125-165.

_ . RBS: Convergência das teles e da TV a cabo. Porto Alegre: PPGCOM/UFRGS, 1999

SCHIRMER, Lauro. RBS: da voz-do-poste à multimídia. Porto Alegre: LP\&M, 2002.

TÉTU, Jean-Francóis. A informação local: espaço público local e suas mediações. In Porto,
Sérgio Dayrell (org.). O jornal - Da forma ao sentido. Brasília, Editora Universidade de Brasília, 2002, p 431-448.

TRAQUINA, Nelson. Jornalismo: questões, teorias e “estórias". Lisboa: Veja, 1993.

- A tribo jornalística - uma comunidade transnacional. Lisboa: Editorial Notícias, 2004.

WAINBERG, Jacques A. A morte dos jornais centenários e o caso do Rio Grande do Sul. In: MOUILLAUD, Maurice; PORTO, Sérgio Dayrell (org.). O Jornal - Da forma ao sentido. Brasília: UnB, 2002, p. 387-410.

ZELIZER, Barbie. Os jornalistas enquanto comunidade interpretativa. In: TRAQUINA, Nelson (org). Jornalismo 2000. Revista de Comunicação e Linguagens. Lisboa: Centro de Estudos de Comunicação e Linguagens, Universidade Nova de Lisboa. Fevereiro 2000, n. 27, p 33-61.

REDE BRASIL SUL - RBS. Disponível em: <http:/ / www.clicrbs.com.br>. Acesso: 21 out. 2006.

ZERO HORA. Disponível em:<http:www.zh.com.br> Acesso em: 21 out. 2006.

\section{ENTREVISTAS}

CAMARGO, Roger. Informações sobre tiragem de Zero Hora [mensagem pessoal]. Mensagem recebida por angelafe@unisc.br em out 2006.

GLEICH, Marta. Circulação de Zero Hora [mensagem pessoal]. Mensagem recebida por angelafe@hotmail.com em out. 2004.

—. Editora-chefe de Zero Hora. Entrevista concedida para autora. Porto Alegre. Dezembro de 2004.

—. Informações sobre o leitor de Zero Hora [mensagem pessoal]. Mensagem recebida por angelafe@unisc.br em out 2006.

RECH, Marcelo. Diretor de Redação de Zero Hora. Entrevista concedida para autora. Porto Alegre. Janeiro de 2006.

STEFANELLI, Ricardo. Editor-chefe de Zero Hora. Entrevista concedida para autora. Porto Alegre. Dezembro de 2004.

XAVIER, Marcelo. Analista de Mercado de Zero Horta. Porto Alegre. Entrevista concedida em janeiro de 2006. 